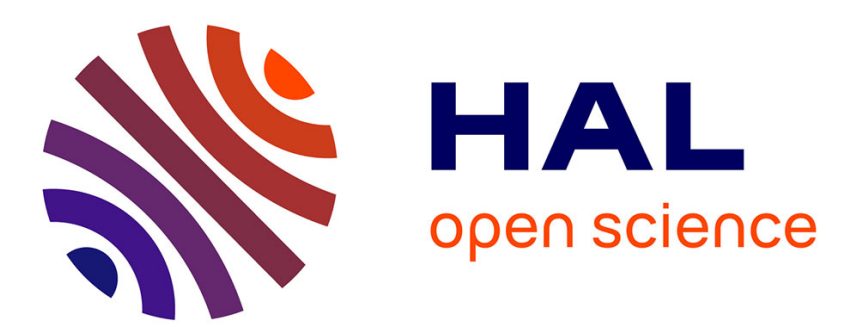

\title{
Magma dynamics feeding Yasur's explosive activity observed using thermal infrared remote sensing
}

\author{
Philipson Bani, Andrew J.L. J.L. Harris, Hiroshi Shinohara, Franck
}

Donnadieu

\section{- To cite this version:}

Philipson Bani, Andrew J.L. J.L. Harris, Hiroshi Shinohara, Franck Donnadieu. Magma dynamics feeding Yasur's explosive activity observed using thermal infrared remote sensing. Geophysical Research Letters, 2013, 40, pp.3830-3835. 10.1002/grl.50722 . hal-01067169

\section{HAL Id: hal-01067169 \\ https://hal.science/hal-01067169}

Submitted on 12 Nov 2021

HAL is a multi-disciplinary open access archive for the deposit and dissemination of scientific research documents, whether they are published or not. The documents may come from teaching and research institutions in France or abroad, or from public or private research centers.
L'archive ouverte pluridisciplinaire HAL, est destinée au dépôt et à la diffusion de documents scientifiques de niveau recherche, publiés ou non, émanant des établissements d'enseignement et de recherche français ou étrangers, des laboratoires publics ou privés. 


\title{
Magma dynamics feeding Yasur's explosive activity observed using thermal infrared remote sensing
}

\author{
Philipson Bani, ${ }^{1,2,3,4}$ Andrew J. L. Harris, ${ }^{1,2,3}$ Hiroshi Shinohara, ${ }^{5}$ and \\ Franck Donnadieu ${ }^{1,2,3}$ \\ Received 13 March 2013; revised 27 June 2013; accepted 4 July 2013; published 2 August 2013.
}

[1] A thermal infrared thermometer was used to record the passage of hot gases and fragments across a measurement area located at the exit of one of Yasur's active vents. Recording was completed over $2 \mathrm{~h}$ during September 2011. A total of 200 explosive events were recorded. We define two types of event: low-energy events with typical thermal energies of $14 \mathrm{~kJ}$ and high-energy events with typical thermal energies of $97 \mathrm{~kJ}$. Around 180 low-energy events were recorded, which together released $457 \mathrm{~kJ}$ of radiant energy. In contrast, only 20 high-energy events were recorded, but they released $2042 \mathrm{~kJ}$. We suggest that low-energy events originate from a relatively shallow, degassed magma reservoir and are associated with bursting of bubbles formed by bubble coalescence during ascent. Instead, high-energy events originate from a relatively deep, fresh magma reservoir and are associated with slugs formed by foam collapse. Citation: Bani, P., A. J. L. Harris, H. Shinohara, and F. Donnadieu (2013), Magma dynamics feeding Yasur's explosive activity observed using thermal infrared remote sensing, Geophys. Res. Lett., 40, 3830-3835, doi:10.1002/grl.50722.

\section{Introduction}

[2] Persistent degassing at an open conduit is often accompanied by bursting of bubbles at the surface of the magmatic column. This propels clouds of hot gas and fragments into the atmosphere during extremely weak explosive events, recently termed bursting [Gurioli et al., 2008] so as to discriminate them from true Strombolian events [Gurioli et al., 2013]. Although weak, this style of repeated, regular, and persistent explosive activity is very hazardous for close approach and excludes any in situ (at-vent) measurement or sampling. However, the active vent, through which hot fragments and gases exit the magmatic conduit, is a study zone of utmost importance as it is the only point through which all magmatic volatiles and particles associated with the explosive emission transit before undergoing profound thermal, physical,

\footnotetext{
${ }^{1}$ Clermont Université, Université Blaise Pascal, Observatoire de Physique du Globe de Clermont-Ferrand, Laboratoire Magmas et Volcans, ClermontFerrand, France.

${ }^{2}$ CNRS, UMR 6524, Laboratoire Magmas et Volcans, ClermontFerrand, France.

${ }^{3}$ IRD, R 163, Laboratoire Magmas et Volcans, Clermont-Ferrand, France.

${ }^{4}$ Center for Volcanology and Geohazards Mitigations, Bandung, Indonesia.

${ }^{5}$ Geological Survey of Japan, AIST, Tsukuba, Japan.

Corresponding author: P. Bani, IRD, R 163, Laboratoire Magmas et Volcans, 5 rue Kessler, FR-63038 Clermont-Ferrand, France. (philipson. bani@ird.fr)

(C)2013. American Geophysical Union. All Rights Reserved. 0094-8276/13/10.1002/grl.50722
}

and chemical changes. Thus, by targeting active vents, studies can gain valuable insights into subsurface magmatic processes that drive the at-vent emission dynamics [e.g., Ripepe et al., 2002; Gresta et al., 2004; Harris and Ripepe, 2007a]. In this case, training an infrared thermal sensor at the vent has proved extremely effective in providing insights into conduit and plume dynamics during explosive events [Ripepe and Harris, 2008; Harris et al., 2008; Sahetapy-Engel et al., 2008]. Thus, to gain insights into the conduit dynamics behind Yasur's persistent degassing and bursting activity [Bani and Lardy, 2007; Oppenheimer et al., 2006; Metrich et al, 2011], we targeted its most active vent with an infrared thermometer to record the continuous thermal signal from the hot gases and fragments ejected as incandescent jets.

[3] Yasur is one of the most active volcanoes in the Vanuatu archipelago. It is a persistently active volcano, where more than 200 years of activity have been recorded since it was first described by Cook in 1774 [Beaglehole, 1961]. Despite its small edifice size ( $361 \mathrm{~m}$, above sea level), it is a major source of volcanic degassing worldwide, releasing $600-700 \mathrm{t} \mathrm{d}^{-1}$ of $\mathrm{SO}_{2}$ into the atmosphere [Bani et al., 2012; Metrich et al., 2011; Bani and Lardy, 2007]. A recent study by Metrich et al. [2011] has indicated that this continuous degassing has led to the accumulation of $25 \mathrm{~km}^{3}$ of degassed and nonerupted magma over the past thousand years. Steady intrusion of this volume is considered responsible for the uplift of Yenkahe resurgent block, which is estimated to have risen $150 \mathrm{~m}$ over the last thousand years [Chen et al., 1995]. Yasur is located on the western part of this Yenkahe block, and its crater currently hosts three active vents, named A, B, and C (Figure 1). These vents are the source of open vent degassing and recurrent explosions which propel hot gases and fragments a few hundred meters above the craters. In this work, thermal infrared recording focused on vent $\mathrm{B}$, this being the most active vent during our observation period.

\section{Methodology}

[4] The thermal infrared survey was carried out in September 2011 using a Land Minolta Cyclops 300. This instrument measures radiance emitted between 8 and $14 \mu \mathrm{m}$, which is converted to a brightness temperature in the range of $-50^{\circ} \mathrm{C}$ to $1000^{\circ} \mathrm{C}$ with accuracy of $\pm 1^{\circ} \mathrm{C}$. The instrument was positioned $200 \mathrm{~m} \mathrm{SW}$ from vent B and pointed just above the active vent. At this distance, given the instrument's $1^{\circ}$ field of view (FOV), measurement area was $9.6 \mathrm{~m}^{2}$ and was filled by the vents' discharge. During each explosion, the thermal emission from the mixture of hot 


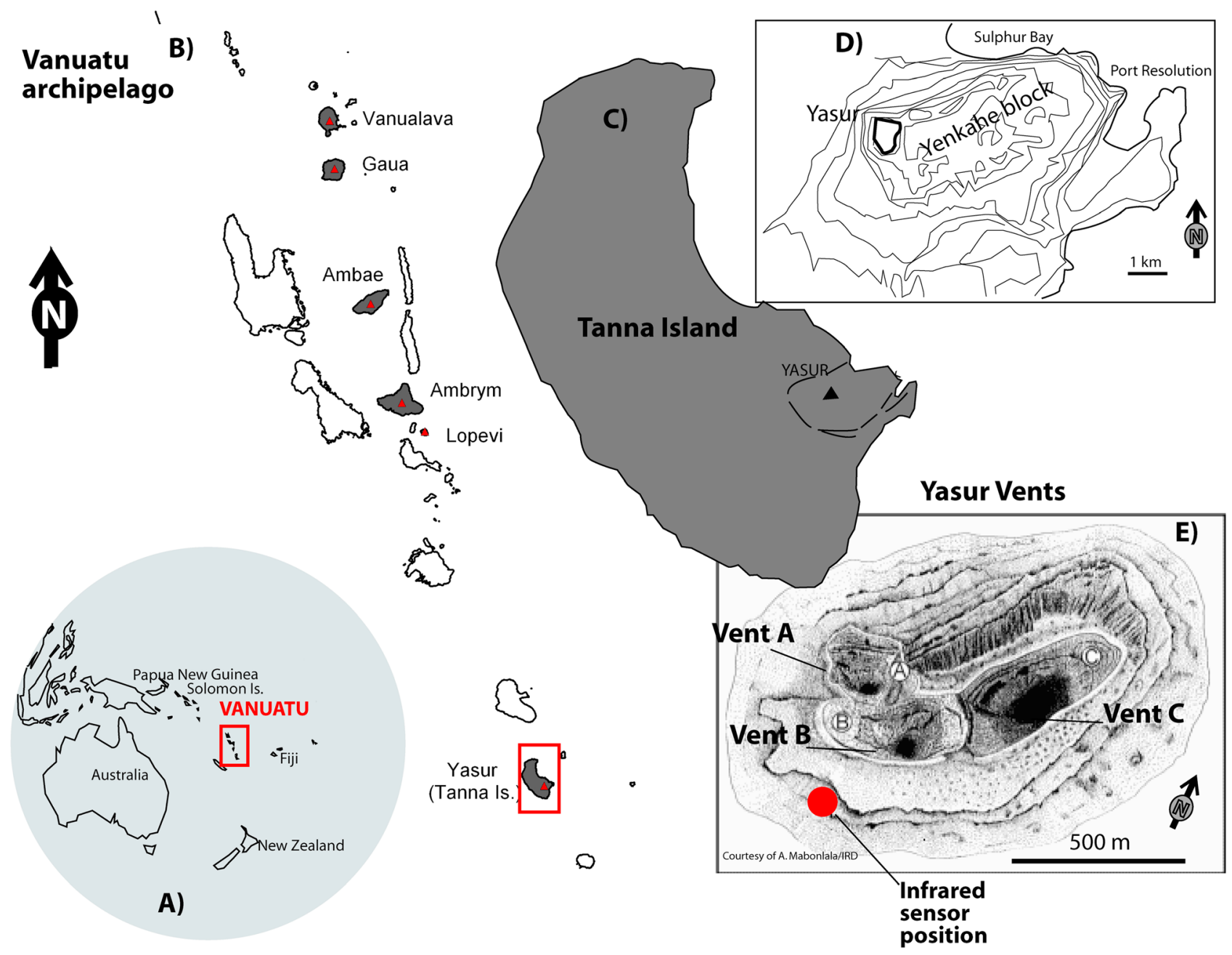

Figure 1. (a) Location of Vanuatu in the southwestern Pacific and the distribution of Vanuatu islands that host active volcanoes (in grey). (b) Yasur, one of the most active volcanoes of Vanuatu, is located on the eastern part of Tanna Island (c) and occupies the western portion of Yenkahe resurgent block (d) and hosts three active vents within its crater (e).

gases and fragments ascending through the FOV triggered a positive thermal response. Between explosions, the instrument also recorded background thermal emissions from the presence of hot magma at a shallow level in the conduit, discharge of hot gases, and subsequent heating of vent wall rock. The thermometer output was sampled using a data logger at the rate of 1 sample/s. Around 7200 data points were recorded for an observation duration of $120 \mathrm{~min}$. To retrieve the true kinetic temperature, correction is required for atmospheric and emissivity effects (see Harris [2013] for all technical and methodological details). However, given that the ejecta is a mixture of hot gases and fragments whose emissivity is difficult to calculate and may vary considerably [Harris, 2013], we chose to focus on the relative signal rather than attempt to convert to absolute (kinetic temperature) values. Hence, we present our data in terms of brightness temperatures which correspond to the integrated thermal radiance for all thermal components within the FOV.

[5] The radiant power flux, $Q_{\text {rad }}$ (in W), was estimated using the Stefan-Boltzmann relation, i.e.,

$$
Q_{\mathrm{rad}}=A \sigma T^{4}
$$

[6] where $\sigma$ is the Stefan-Boltzman constant $\left(5.67 \times 10^{-8} \mathrm{~W} \mathrm{~m}^{-2} \mathrm{~K}^{-4}\right), T$ is the recorded temperature (in $\mathrm{K}$ ), and $A$ is the FOV area. To estimate the total radiant energy $\left(E_{\mathrm{rad}}\right.$, in $\left.\mathrm{J}\right)$ associated with each burst, we summed all radiant power fluxes recorded during the event, i.e.,

$$
E_{\text {rad }}=A \sigma\left(T_{i}{ }^{4}-T_{0}{ }^{4}\right)
$$

where $T_{0}$ is the background temperature (this being the temperature recorded just before the explosion), and $T_{i}$ is the $i$ th temperature recorded.

\section{Results}

[7] Explosive events were recorded as around 200 peaks in the $2 \mathrm{~h}$ long time series (Figure 2). Every peak corresponded to an incandescent jet of hot gases and fragments from the active vent, suggesting a continuous flow of bubbles in the conduit with large bubbles bursting at a rate of 1-2 bursts/min. This compares with 30-60 bursts/min at Stromboli [Harris and Ripepe, 2007a] and $\sim 9$ bursts/min at Villarrica [Gurioli et al., 2008]. The maximum brightness temperature 


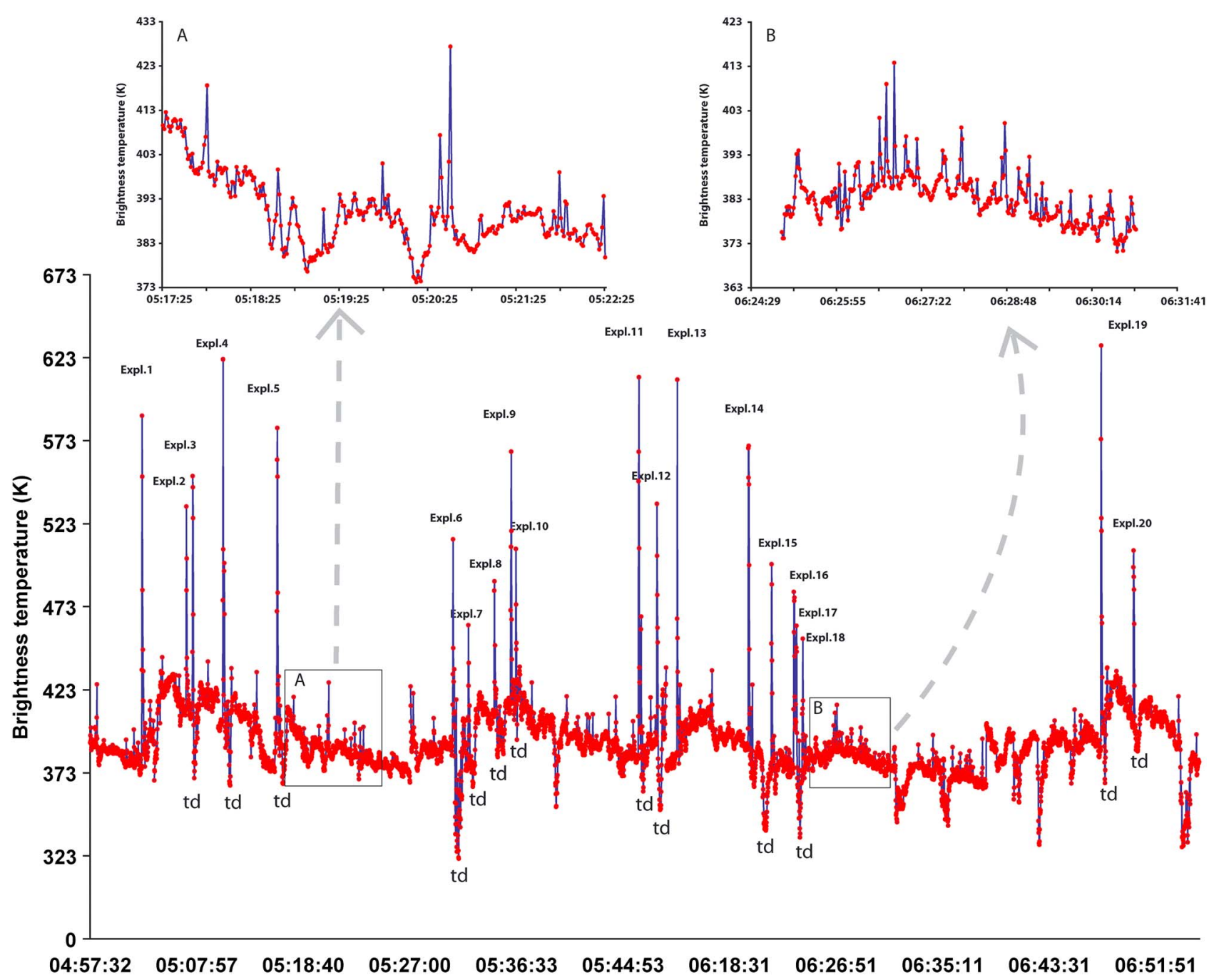

Figure 2. Two hours of continuous thermal record for Yasur's B vent. Twenty high-energy events are marked by brightness temperatures that strongly exceed the background thermal level. Around two thirds of the high-energy events were followed by a thermal drop (td). The two zooms ( $\mathrm{a}$ and $\mathrm{b}$ ) highlight the waveforms recorded during low-energy events.

recorded during the peaks $\left(T_{\max }\right)$ varied between 358 and $630 \mathrm{~K}$. Background brightness temperatures between peaks $\left(T_{\text {back }}\right)$ fluctuated between 345 and $427 \mathrm{~K}$, so that the thermal amplitude $\left(=T_{\max }-T_{\text {back }}\right)$ fluctuated between 5 and $243 \mathrm{~K}$. The duration of explosions varied between 3 and $11 \mathrm{~s}$, and the explosion onset phase (the time required to move from $T_{\text {back }}$ to $T_{\text {max }}$ ) lasted between 1 and $4 \mathrm{~s}$ (Figure 3 ). The total radiant energy for individual bursts fluctuated between 0.3 and $217 \mathrm{~kJ}$ (Figure 4).

[8] Twenty high-energy events are apparent from particularly high values of $T_{\max }$ (Figure 2). Among these 20 more violent explosions, 13 displayed double peaks (Figure 3). Thus, more than half of the high-energy events comprised two bursts separated by $2-7 \mathrm{~s}$. Figure 4 shows a good correlation between the total radiant energy of the eruptions and the corresponding eruption onset. That is, the shorter the onset, the greater the radiant energy. According to Bani and Lardy [2007], Yasur's high-energy events fluctuate between $\sim 1$ event/h when the activity is at relatively low levels and more than 20 events/h when the system is very active. Thus, given 10 events/h, Yasur's activity was in a phase of moderate activity during our observations.
[9] After some explosive events, we recorded a decrease in the thermal signal (Figure 2), with the brightness temperature dipping well below the background level for 20-40 s following the event. Two thirds of the high-energy events recorded were followed by such a decrease. The time lag between the eruption onset and the beginning of the drop in thermal signal varied between 5 and $20 \mathrm{~s}$. Such thermal decreases have not been recorded during explosions at Stromboli [e.g., Harris and Ripepe, 2007a, 2007b]. However, they have been recorded after explosions at Santiaguito due to obscuration of the hot source by cold ash [Sahetapy-Engel et al., 2004]. However, low ash content during even vigorous discharges at Yasur precludes occultation by ash as the source of the thermal drop. Such drops have been also recorded before, but not after, repeated gas piston events at Pu'u 'O'o [Marchetti and Harris, 2008] and at linked vents on Stromboli where the degassing vent undergoes a decline synchronous with an explosion at the second, linked, vent [Harris et al., 1996]. In this latter case, the temperature decline may be a pressure effect that causes the vent to suck in cold air during release of pressure at the linked vent. 


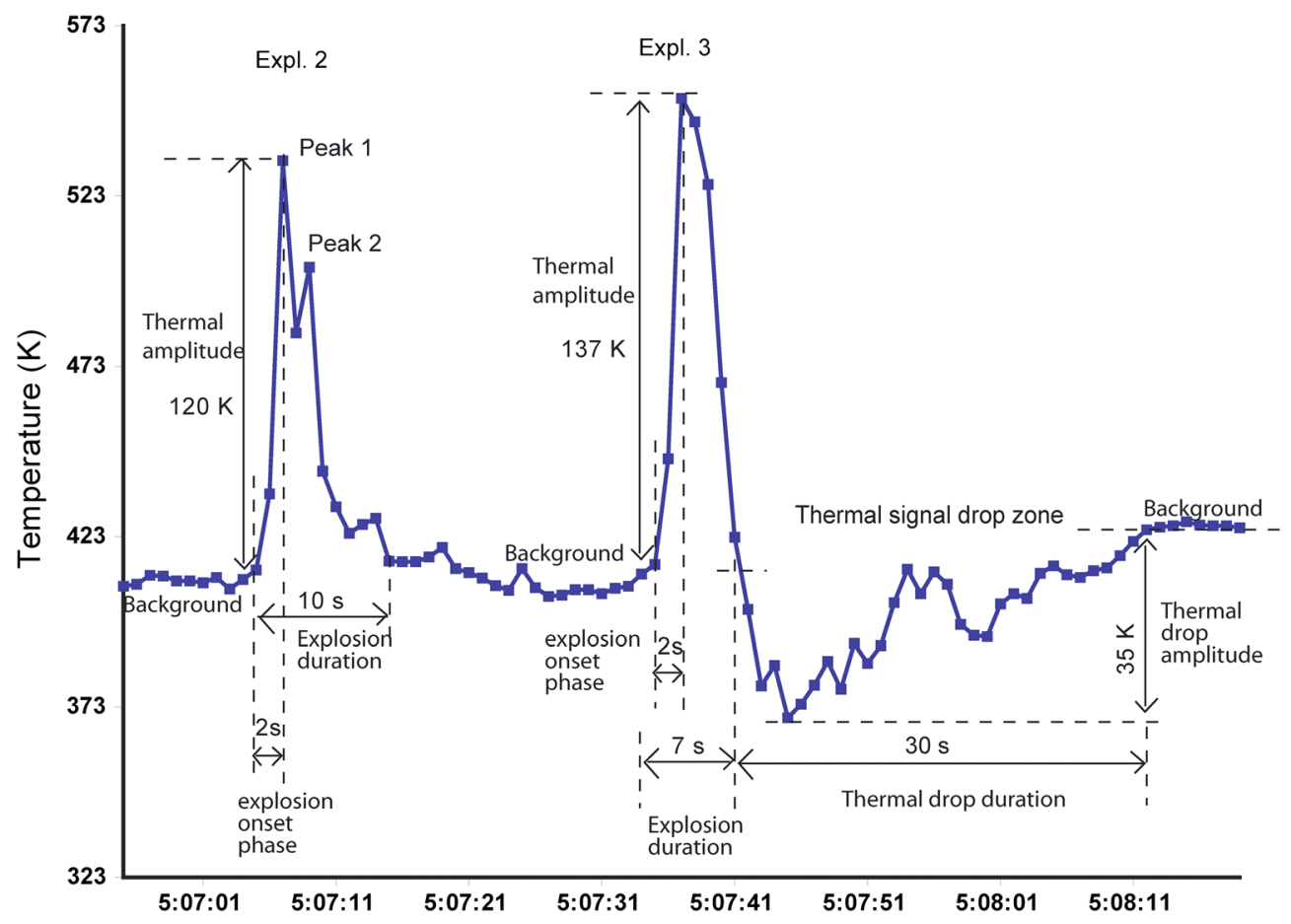

Figure 3. Typical thermal signals recorded during high-energy events: (i) double peaks (Expl. 2) and (ii) single peak (Expl. 3). Note the thermal drop following Expl. 3.

\section{Discussion}

[10] We define two distinct groups of bursts. Group 1 events are minor bursts. These have an average thermal amplitude of $3.2 \mathrm{~K}$ and a total radiant energy of $14 \mathrm{~kJ}$. Group 2 events are high-energy bursts. These have a mean thermal amplitude of $139 \mathrm{~K}$ and an average total radiant energy of $97 \mathrm{~kJ}$. Group 1 events made up a large majority $(87 \%)$ of the recorded events (Figure 4). However, the cumulative radiant energy for Group 1 events over the recorded period only reached $457 \mathrm{~kJ}$, much lower than the $2042 \mathrm{~kJ}$ from the 20 high-energy events. These two groups are further differentiated in Figure 4, where we plot the radiant energy versus thermal amplitude. In addition to the strong correlation observed between radiant energy and thermal amplitude, Figure 4 indicates that minor bursts display thermal amplitudes of less than $50 \mathrm{~K}$ and radiant energies not greater than $12 \mathrm{~kJ}$. It is thus evident that Yasur's bursting activity is sustained by two different magma dynamics. These may be related to two degassing regimes: the background degassing regime, maintained by the frequent bursting of relatively small gas batches, and less frequent bursting of relatively large gas batches (to feed the high-energy events). This dual degassing system on Yasur was first highlighted in 2006 by Oppenheimer et al. [2006] using open-path Fourier transform infrared (FTIR) spectroscopy. They observed a much higher $\mathrm{SO}_{2} / \mathrm{HCl}$ ratio $(\sim 30)$ during Yasur's high-energy events, contrasting with a much lower ratio $(\sim 2)$ obtained during passive degassing (and bursting). They concluded that there were two main gas sources: one deeper and rich in $\mathrm{CO}_{2}$ and $\mathrm{SO}_{2}$ and the other shallow and supplying most of the $\mathrm{HCl}$ emitted. Metrich et al. [2011] further constrained Yasur's feeding system and provided a model of its plumbing system that suggested shallow emplacement of degassed magma connected to a deeper undegassed basaltic-trachyandesite magma that sustains Yasur's eruptive activity. Our results are therefore consistent with a model in which numerous minor low-radiant energy bursts are sourced from a shallow magma reservoir, and the more violent high-radiant energy bursts are sustained by the deeper source (i.e., deep-forming bubbles). This situation is comparable to what was observed on Stromboli with similar volcanic activity where slugs are generated at $3 \mathrm{~km}$ deep [Burton et al., 2007]. However, in contrast to this latter study two different techniques deployed on Yasur, including an FTIR spectrometer [Oppenheimer et al., 2006] and multigas instruments [Metrich et al., 2011] both indicated steady $\mathrm{CO}_{2} / \mathrm{SO}_{2}$ ratios in the gas emissions, despite the strong fluctuation in $\mathrm{S} / \mathrm{Cl}$ ratios observed with the FTIR. Thus, the deep source degassing regime on Yasur has yet to be consistent with gas composition data. Kremers et al. [2012] have recently suggested, based a combined petrology, geochemistry, and rheology analyses of Yasur eruptive products, that the frequent recurrence of weak and short events may favor longer residency of most of the shallow magma, thereby inducing crystallization and a higher magma oxidation state, while the less frequent and stronger events incorporating larger volumes of more shallow magma may shorten the overall residency of magma in the shallow conduit. This is consistent with our findings that the highradiant energy bursts, although less frequent, remove $80 \%$ of the total thermal energy lost from the system during explosive events, which during our recording period was $2500 \mathrm{~kJ}$.

[11] The magma dynamics beneath systems active with Strombolian activity has been explained by two models: a "collapsing foam model" and a "rise speed-dependent model" [e.g., Parfitt, 2004]. The first model suggests that bubbles accumulate to form a foam layer. Collapse of the foam produces a large gas pocket or slug of gas that rises up the conduit, bursting at the surface as a Strombolian event [Jaupart and Vergniolle, 1988; Vergniolle and Jaupart, 1990; 

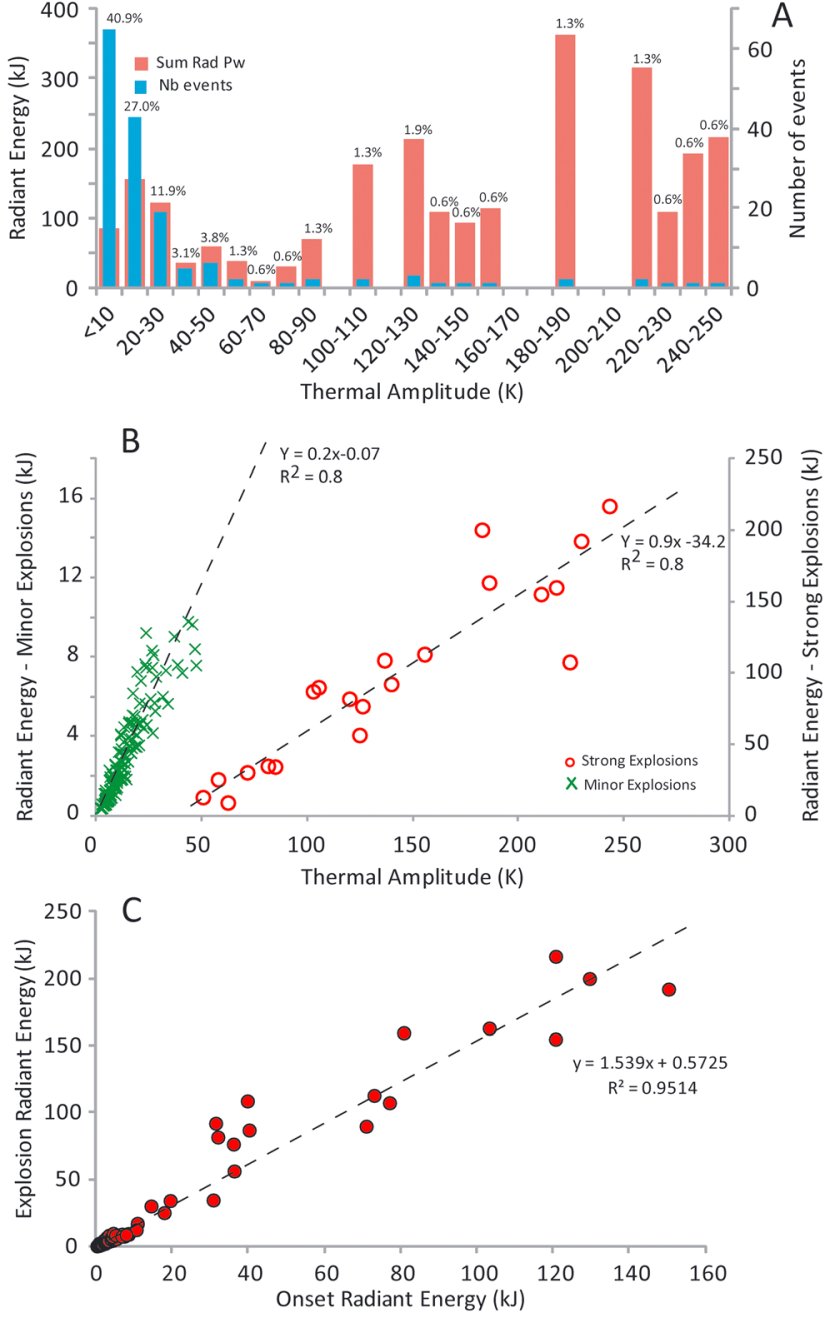

Figure 4. Radiant power output from Yasur's B vent. (a) Number of bursts and their corresponding radiant energy and thermal amplitude. The percentage of events per group is indicated. (b) Correlation between thermal amplitude and radiant energy. This chart also differentiates the two burst types: low energy and high energy. (c) Correlation between the radiant energy of eruptions and their corresponding onset radiant energy.

Vergniolle et al., 2004]. In the second model, Strombolian eruptions are assumed to result from bubble coalescence. When bubbles are formed in the melt, they grow by diffusion and decompression. They then rise through the magma. Larger bubbles rise faster than smaller bubbles and are thus able to coalesce with smaller bubbles that they intercept on their way. This process can lead to the formation of huge bubbles that sustain Strombolian bursts [Oppenheimer et al., 2006; Parfitt, 2004]. The magma dynamics that feeds Yasur's bursting activity may combine these two models.

[12] If we assume that radiant energy carried by each burst is proportional to bubble size, then the wide range of radiant energy from $\sim 20$ to $220 \mathrm{~kJ}$ (Figure 4) suggests arrival at the surface of different sized bubbles. Further, the arrival of larger bubbles is not random but tends to occur in clusters separated by a 5-30 min hiatus (Figure 5), and in general, the first burst of each group has (in most cases) the highest energy. Although longer time series data are necessary to

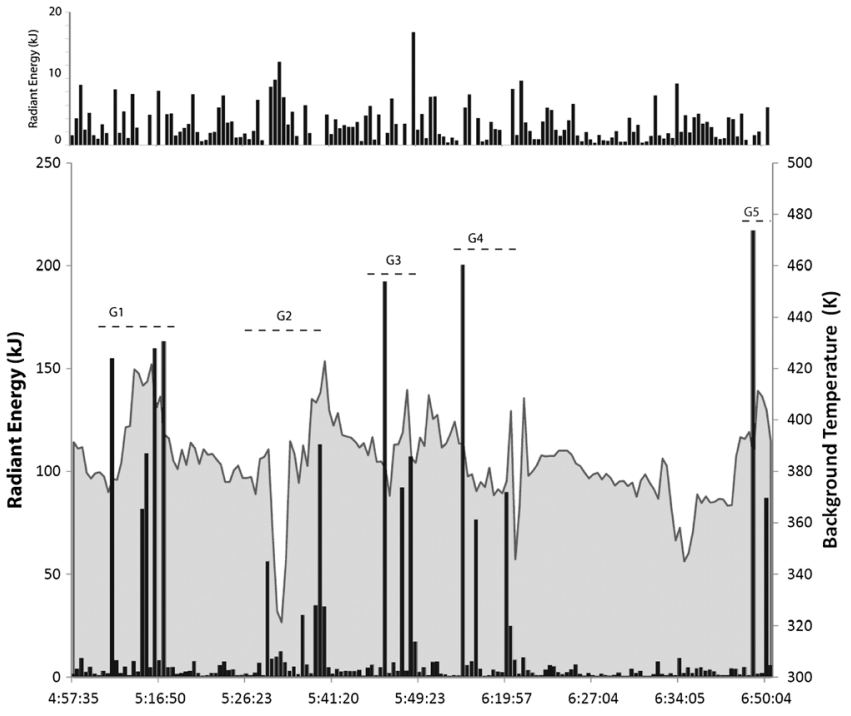

Figure 5. Changes in the background temperature following bursts. The occurrence of high-energy clusters (G1-G5) tends to increase background temperature. Note the strong drop in background temperature at around 6:34 with no associated explosion, which may probably have been enhanced by eruptive discharge on vent $\mathrm{A}$ or $\mathrm{C}$.

draw robust conclusions, we suggest that these bursts are fed by foam layer collapse, where the hiatus is the time required to regenerate the foam. The quiescent periods between high-energy event clusters are still characterized by frequent bubble bursting, albeit of much lower energy. We suggest that this steady flux is fed by a continuous supply of gas from the shallow source, where bubbles organize themselves following the rise speed-dependent model.

[13] Our measurements also indicate that the occurrence of deep-forming bubbles did not have any significant influence on the occurrence of minor bursts, suggesting limited interference on the dynamics of the shallow reservoir. However, as depicted in Figure 5, deep-forming bubbles appear to play a role in the short decreases in the degassing rate, magma level, or pressurization in the conduit. That is, their arrival is followed by a temperature decline that can be explained by a decline in degassing [Harris and Ripepe, 2007a], magma level [Harris and Stevenson, 1997], and/or sucking of air [e.g. Harris et al., 1996]. A simple explanation is that the arrival of large bubbles increases the volume of the gasmagma mixture in the conduit and subsequently increases the magma level in the conduit (Figure 6). The loss of volume during bubble burst results in a drop in magma level, depressurization, and sucking.

\section{Conclusion}

[14] Continuous thermal infrared measurements of explosive emissions at an active vent can be a valuable complementary approach to investigate the magma dynamics that feed the activity. Two magma degassing regimes beneath Yasur are very well defined. We suggest that deep-forming bubbles likely sustain high-energy bursts that comprise $13 \%$ of events but account for $80 \%$ of the thermal energy carried by explosive emissions. Low-energy events originating from a shallower magma reservoir account for $87 \%$ of the 


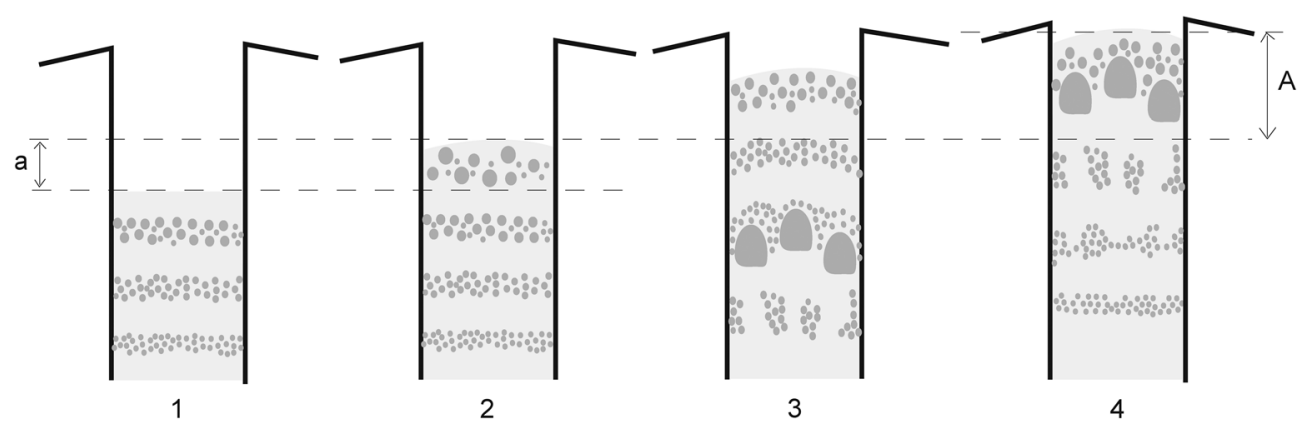

Figure 6. Sketch of the magma dynamics beneath Yasur (a) continuous degassing feeds minor incandescent jets (1, 2). (b) Arrival of deep-forming bubble groups increases the volume in the conduit, causing a higher amplitude (A) and magma-level changes $(3,4)$. The loss of bubbles leads to the loss of magma volume, thus lowering the magma level in the conduit, depressurization, and/or sucking.

events but only $20 \%$ of the thermal energy released by explosions. Measurements further suggest that the magmalevel fluctuation in the conduit is controlled by the total volume of bubbles in the conduit.

[15] Acknowledgments. We thank the Vanuatu Geohazards group for facilitating the field work. We acknowledge support from the Japan Society for the Promotion of Science (to P.B. and H.S.) and from the Agence National de la Recherche through the Arc-Vanuatu project (to P.B. and F. D.). A.H. thanks the Region d'Auvergne for support through the Chaire d'Excellence and FEDER.

[16] The Editor thanks Sharon Allen and an anonymous reviewer for their assistance in evaluating this paper.

\section{References}

Bani, P., and M. Lardy (2007), Sulphur dioxide emission rates from Yasur volcano, Vanuatu archipelago, Geophys. Res. Lett., 34, L20309, doi:10.1029/2007GL030411.

Bani, P., C. Oppenheimer, P. Allard, S. Shinohara, V. Tsanev, S. Carn, M. Lardy, and E. Garaebiti (2012), First estimate of volcanic $\mathrm{SO}_{2}$ budget for Vanuatu island arc, J. Volcanol. Geotherm. Res., 211-212, 36-46.

Beaglehole, J. C. (1961), The Journals of Captain James Cook on His Voyages of Discovery, vol. II. The Voyage of the Resolution and Adventure, Hakluyt Soc. Extra Ser. 36 Cambridge Univ. Press, Cambridge, U.K., pp. 1772-1775.

Burton, M., P. Allard, F. Muré, and A. La Spina (2007), Magma gas composition reveals the source depth of slug-driven strombolian explosive activity, Science, 317, 227-230.

Chen, J. K., F. W. Taylor, R. L. Edwards, H. Cheng, and G. S. Burr (1995), Recent emerged reef terraces of the Yenkahe resurgent block,Tanna, Vanuatu: Implications for volcanic, landslide and tsunami hazards, J. Geol., 103, 577-590.

Gresta, S., M. Ripepe, E. Marchetti, S. D’Amico, M. Coltelli, A. J. L. Harris, and E. Privitera (2004), Seismoacoustic measurements during the JulyAugust 2001 eruption of Mt. Etna volcano, Italy, J. Volcanol. Geotherm. Res., 137, 219-230.

Gurioli, L., A. J. L. Harris, B. F. Houghton, M. Polacci, and M. Ripepe (2008), Textural and geophysical characterization of explosive basaltic activity at Villarrica volcano, J. Geophys. Res., 113, B08206, doi:10.1029/2007JB005328.

Gurioli, L., A. J. L. Harris, L. Colò, J. Bernard, M. Favalli, M. Ripepe, and D. Andronico (2013), Classification, landing distribution and associated flight parameters for a bomb field emplaced during a single major explosion at Stromboli, Geology, doi:10.1130/G33967.1.

Harris, A. J. L., N. F. Stevens, A. J. H. Maciejewski, and P. J. Röllin (1996), Thermal evidence for linked vents at Stromboli, Acta Vulcanol., 8, 57-62.

Harris, A. J. L., and D. S. Stevenson (1997), Magma budgets and steadystate activity of Vulcano and Stromboli volcanoes, Geophys. Res. Lett., 24(9), 1043-1046.
Harris, A. J. L., and M. Ripepe (2007a), Temperature and dynamics of degassing at Stromboli, J. Geophys. Res., 112, B03205, doi:10.1029/ 2006JB004393.

Harris, A. J. L., and M. Ripepe (2007b), Synergy of multiple geophysical approaches to unravel explosive eruption conduit and source dynamics -A case study from Stromboli, Chem. Erde, 67, 1-35.

Harris, A. J. L., M. Ripepe, S. Calvari, L. Lodato, and L. Spampinato (2008), The 5 April 2003 explosion of Stromboli: Timing of eruption dynamics using thermal data, $A G U$ Monogr. "Learning From Stromboli," Geophys. Monogr., 182, 305-316.

Harris, A. J. L. (2013), Thermal Remote Sensing of Active Volcanoes: A User's Manual, Cambridge Univ. Press, Cambridge, U. K.

Jaupart, C., and S. Vergniolle (1988), Laboratory model of Hawaiian and Strombolian eruptions, Nature, 331, 58-60, doi:10.1038/331058a0.

Kremers, S., Y. Lavallée, J. Hanson, and K.-U. Hess (2012), Shallow magma-mingling-driven Strombolian eruptions at Mt. Ieyasu volcano, Vanuatu, Geophys. Res. Lett., 39, L21304, doi:10.1029/ 2012GL053312.

Marchetti, E., and A. J. L. Harris (2008), Trends in activity at Pu'u 'O'o during 2001-2003: insights from the continuous thermal record, Geol. Soc. Spec. Publ., 307, 85-101, doi:10.1144/SP307.6.

Métrich, N., et al. (2011), Magma and volatile supply to post-collapse volcanism and block resurgence in Siwi Caldera (Tanna Island, Vanuatu Arc), J. Petrol., doi:10.1093/petrology/erg019.

Oppenheimer, C., P. Bani, J. A. Calkins, M. R. Burton, and G. M. Sawyer (2006), Rapid FTIR sensing of volcanic gases released by Strombolian explosions at Yasur volcano, Vanuatu, Appl. Phys. B, doi:10.1007/ s00340-006-2353-4.

Parfitt, E. A. (2004), A discussion on the mechanisms of the explosive basaltic eruptions, J. Volcanol. Geotherm. Res., 134, 77-107.

Ripepe, M., A. J. L. Harris, and R. Carniel (2002), Thermal, seismic and infrasonic evidences of variable degassing rates at Stromboli volcano, J. Volcanol. Geotherm. Res., 118, 285-207.

Ripepe, M., and A. J. L. Harris (2008), Dynamics of the 5 April 2003 explosive paroxysm observed at Stromboli by a near-vent thermal, seismic and infrasonic array, Geophys. Res. Lett., 35, L07306, doi:10.1029/ 2007GL032533.

Sahetapy-Engel, S. T. M., L. P. Flynn, A. J. L. Harris, G. J. Bluth, W. I. Rose, and O. Matias (2004), Surface temperature and spectral measurements at Santiaguito Lava Dome, Guatemala, Geophys. Res. Lett., 31, L19610, doi:10.1029/2004GL020683.

Sahetapy-Engel, S. T., A. J. L. Harris, and E. Marchetti (2008), Thermal, seismic and infrasound observations of persistent explosive activity and conduit dynamics at Santiaguito Lava Dome, Guatemala, J. Volcanol. Geotherm. Res., 173, 1-14.

Vergniolle, S., and C. Jaupart (1990), Dynamic of degassing at Kilauea Volcano, Hawaii, J. Geophys. Res., 95(B3), 2793-2809.

Vergniolle, S., M. Boichu, and J. Caplan-Auerbach (2004), Acoustic measurements of the 1999 eruption of Shishaldin volcano, Alaska, (1) Origin of Strombolian activity, J. Volcanol. Geotherm. Res., 137, 109-134. 